\title{
A FREQUENCIA DE AUTOMEDICAÇÃO POR PACIENTES EM ATENDIMENTO ODONTOLÓGICO DE URGÊNCIA NA ATENÇÃO BÁSICA
}

\author{
FREQUENCY OF PATIENTS SELF MEDICATION IN DENTAL \\ EMERGENCY CARE IN PRIMARY CARE
}

\author{
Claudia Santos Souza', Lídia Audrey Rocha Valadas Marques², \\ Márcio Glauber Lopes de Aguiar ${ }^{3}$, Raquel Maria Trindade Fernandes ${ }^{4}$
}

\section{RESUMO}

A avaliação do consumo de medicamentos é uma importante ferramenta para garantir o acesso e avaliar seu uso racional. Embora estudos indiquem a relação entre 0 aumento da resistência dos microrganismos e o uso irracional de medicamentos, poucos dados de Farmacoepidemiologia e do perfil desses pacientes estão disponíveis em Odontologia. Objetivo: Avaliar o consumo de medicamentos utilizados de forma irracional pela população que procura atendimento de urgência em Odontologia em unidades de saúde da atenção básica no município de Aracati- CE. Metodologia: Trata-se de estudo descritivo, onde foram avaliados dados como idade, gênero do paciente, queixa principal, medicamentos utilizados previamente ao atendimento sem prescrição e tratamento proposto. Resultados: No período estudado 176 pacientes buscaram o serviço de urgência do posto de saúde principalmente devido a dor de dente. Dentre eles 140 (79,5\%) estavam se automedicando, 65\% era do sexo feminino e $35 \%$ do sexo masculino, com média de 33 anos de idade. Aamostra se caracterizou principalmente por pessoas com baixa renda e escolaridade, que se automedicavam frequentemente. Conclusão: A automedicação é algo freqüente na vida das pessoas e seus riscos muitas vezes desconhecidos. Percebe-se a necessidade de trabalhar temas como uso racional de medicamentos e a presença de profissionais farmacêuticos em unidades básicas de saúde da Estratégia de Saúde da Família.

Descritores: Medicamentos sem prescrição; Odontalgia; Atenção Primária à Saúde.

\section{ABSTRACT}

The evaluation of the drugs consumption is an important tool to ensure access and evaluate their rational use. Although studies indicate the relationship between the increasing resistance of microorganisms and the irrational use of medicines, few Pharmacoepidemiology data and profile of these patients are available in dentistry. Objective: To evaluate the consumption of drugs used irrationally by patients seeking urgent care in dentistry in health units of primary care in the Aracati- CE city. Methodology: This is a descriptive study that evaluated data such as age, gender, chief complaint, medications previously used service without prescription and proposed treatment. Results: During the period study 176 patients sought urgent department health of the basic health units mainly due to toothache. Among them 140 $(79.5 \%)$ were self-medicating, $65 \%$ were female and $35 \%$ male, mean age of 33 years old. The sample was characterized mainly by people with low income and education, which are often self-medicated. Conclusion: Self-medication is something frequent in the lives of people and their often unknown risks. You see the need to work issues such as rational use of drugs and the presence of pharmaceutical professionals in basic health units of the Family Health Strategy.
${ }^{1}$ Formada em Farmácia pelo Instituto Florence de Ensino Superior (FLORENCE), São Luís, MA, Brasil.

2 Doutoranda em Desenvolvimento de Medicamentos pela Universidade Federal do Ceará (UFC), Fortaleza, CE, Brasil.

${ }^{3}$ Formado em Odontologia pela Universidade Federal do Ceará (UFC), Fortaleza, CE, Brasil.

${ }^{4}$ Doutorado em Química pela Universidade Estadual de Campinas (UNICAMP), Campinas, SP, Brasil. 


\section{Introdução}

A automedicação é um procedimento caracterizado especialmente pela iniciativa de um paciente ou seu responsável, em utilizar um medicamento por acreditar que o mesmo lhe trará benefícios no tratamento de doenças ou alívio de sintomas. A automedicação assim como a prescrição equivocada pode ter como conseqüência diversos riscos à saúde do paciente, como efeitos colaterais, enfermidades e mascaramento de doenças, muitas vezes aumentando 0 problema ao invés de solucioná-lo1. Isso é algo potencialmente nocivo à saúde humana individual e coletiva, pois todo medicamento age de alguma maneira no organismo. $O$ uso de medicamentos seja ele qual for, sem uma orientação profissional pode acarretar diversas conseqüências entre elas a resistência bacteriana, reações de hipersensibilidade, dependência, sangramento digestivo, hepatopatia, sintomas de retirada, além do risco para determinadas neoplasias².

A Organização Mundial de Saúde (OMS) afirma que para um correto uso de medicamentos, é preciso, em primeiro lugar, estabelecer a real necessidade do mesmo e a correta prescrição pelo profissional de saúde. Entretanto no Brasil a realidade se contrapõe à proposta da OMS. Em média 35\% dos medicamentos utilizados são utilizados de forma irracional. Vários são os fatores relacionados a isso, entre eles se encontram o desconhecimento dos riscos, a falta de acesso aos serviços de saúde, etc ${ }^{3}$.

De natureza multifatorial, a automedicação está relacionada a fatores econômicos, políticos e culturais, que têm contribuído para o crescimento e a difusão do uso irracional de medicamentos pelo mundo, tornando-o um problema de saúde pública. Uma maior disponibilidade de produtos no mercado e o acesso aos mesmos gera maior familiaridade do usuário leigo com os medicamentos ${ }^{4}$.

Não há duvidas sobre os benefícios da terapêutica medicamentosa no combate às diversas moléstias que acometem a humanidade, entretanto, em algumas situações seu uso causa efeitos indesejáveis à saúde, como reações adversas. O profissional farmacêutico deve atuar de forma efetiva na assistência ao paciente, sendo que a ação central da prática farmacêutica deve ser promover o uso racional de medicamentos ${ }^{5}$. Quando corretamente prescrito 0 antimicrobiano pelo profissional responsável, cabe ao Farmacêutico a orientação e acompanhamento na administração do mesmo, proporcionando maior segurança e eficiência na terapêutica ${ }^{6}$.

A terapêutica medicamentosa, prática utilizada em todas as modalidades clínicas, na Odontologia ainda tem seu uso irracional pouco estudado. Poucos são os estudos realizados sobre os medicamentos em Odontologia e a automedicação, dentre os quais antimicrobianos, antiinflamatórios não-esteróides e os analgésicos se destacam? ${ }^{7}$. Várias são as reações adversas que podem ser causada pelo uso irracional de analgésicos, antiinflamatórios e antimicrobianos, que são as classes mais prescritas em Odontologia8,9,10.

Objetivou-se neste trabalho avaliar a utilização dos medicamentos na prática da clínica odontológica, em especial os antimicrobianos, bem como o perfil desses pacientes.

\section{Metodologia}

\subsection{Tipo de estudo}

Trata-se de um estudo de caráter descritivo, transversal, com análise quantitativa dos dados. 0 presente estudo foi aprovado conforme a Resolução 466/12, sob parecer 1.292.496.

\subsection{Período, população e Local da pesquisa}

O estudo foi realizado em um posto de atenção básica com serviço odontológico no município de Aracati-CE. A população deste estudo foi de pacientes que buscaram serviço de urgência em Odontologia no referido posto no período de novembro de 2015 a maio de 2016. Foram incluídos no estudo pessoas acima de 18 anos que buscaram o serviço de urgência odontológica para assim ser avaliada a freqüência da automedicação. Foram excluídos do estudo pacientes desdentados ou que se automedicaram por outras patologias ou queixas não relacionadas a cavidade bucal. 


\subsection{Instrumentos de coleta de dados}

O instrumento de coleta de dados foi um questionário do estudo respondido pelos pacientes onde foram avaliados dados como idade, gênero do paciente, queixa principal, medicamentos utilizados previamente ao atendimento sem prescrição e tratamento proposto.

\subsection{Análise dos dados}

Após a coleta dos dados, os mesmos foram analisados em Programa Excel (versão 2010) e demonstrados em forma de tabelas e figuras e serão expressos em percentual e frequencia.

\section{Resultados e Discussão}

A Organização Mundial de Saúde (OMS) recomenda que para o correto uso do medicamento, antes de tudo devese estabelecer a necessidade do uso e a escolha do medicamento apropriado para assim ser feita sua prescrição. A promoção ao uso racional de medicamentos é algo bastante complexo e relacionado a vários fatores, entre eles sociais e culturais, sendo essencial a educação e instrução da população quanto aos riscos. A familiaridade das pessoas com os medicamentos, experiências que obtiveram êxito juntamente a dificuldade de acesso a serviços de saúde acabam se tornando fortes fatores que contribuem para o uso indevido do medicamento ${ }^{1}$.

No período estudado 176 pacientes buscaram o serviço de urgência da Unidade Básica de Saúde Nova Barreira no município de Aracati- CE. Dentre eles 140 (79,5\%) afirmaram que estavam se automedicando.

Entre os pacientes que se encontravam dentro dos critérios de inclusão 65\% (91) era do sexo feminino e $35 \%$ (49) do sexo masculino. A média de idade desses pacientes foi de 33 anos. A maioria era do ensino fundamental incompleto 91 (65\%) e possuíam renda de até 1 salário mínimo 66,4\% (93). No estudo de Vilarino et al.(1998), que avaliou o perfil de usuários que se automedicavam, identificou que a maioria são do sexo feminino, com idade média de 28 anos e com alto grau de instrução. (Quadro 1) Outros estudos demonstram que não existe uma associação consistente entre idade e o uso irracional de medicamentos ${ }^{6}$.

Nos resultados do estudo de Arrais et al., 1997,1 sugerem que a automedicação no Brasil é praticada principalmente por mulheres, entre 16 e 45 anos. Entre os homens, esses dados se mostram mais comuns nas idades extremas. De acordo com o autor, a predominância da automedicação pelas mulheres tem um contexto relacionado ao papel social que tradicionalmente é atribuído às mulheres na família. De acordo com o estudo de Vileti et al., ${ }^{9} 2009$, pessoas do sexo feminino sentem mais dor em geral quando comparadas ao sexo masculino, sendo assim as mulheres acabam comprando mais medicamentos que os homens.

Quanto ao grau de escolaridade a literatura se apresenta controversa quanto a automedicação, alguns estudos apontam um maior consumo de medicamentos por pacientes com um maior grau de escolaridade, provavelmente pelo fato de terem acesso a maiores informações que os auxiliam na escolha do consumo, e os tornando confiantes para se automedicarem. Sendo assim pode-se considerar que o nível econômico e social são muito difíceis de serem interpretados como influentes em um estudo envolvendo uso indevido de medicamentos ${ }^{8}$.

Quadro 1: Perfil dos pacientes que se automedicavam que buscaram o serviço de urgência da UBS.

\begin{tabular}{|c|c|c|}
\hline & $\mathrm{n}$ & $\%$ \\
\hline Sexo & & \\
\hline Feminino & 91 & $65 \%$ \\
Masculino & 49 & $35 \%$ \\
\hline Idade & & \\
\hline Masculino & 49 & $35 \%$ \\
\hline Idade & & $7,0 \%$ \\
\hline
\end{tabular}




\begin{tabular}{|c|c|c|}
\hline 18 a 20 anos & 11 & $7,0 \%$ \\
20 a 30 anos & 59 & $7,0 \%$ \\
30 a 40 anos & 40 & $7,0 \%$ \\
40 a 50 anos & 11 & $8,5 \%$ \\
50 a 60 anos & 12 & $5,0 \%$ \\
>60 anos & 7 & \\
\hline Escolaridade & & \\
\hline Sem escolaridade & 9 & $6,0 \%$ \\
Fundamental & 91 & $65,0 \%$ \\
Incompleto & 27 & $19,2 \%$ \\
Médio Incompleto & 12 & $8,5 \%$ \\
Médio completo & 1 & $0,7 \%$ \\
Superior incompleto & & \\
\hline Renda mensal & & \\
\hline Sem renda & 29 & \\
Eté 1 salário mínimo & 93 & $0,7 \%$ \\
Entre 1 e 2 salários & 12 & \\
mínimos & 1 & \\
\hline mínimos & & \\
\hline
\end{tabular}

A média de idade dos pacientes foi de 33 anos.

Dados expressos em forma de frequência absoluta e percentual.

O principal motivo da procura do atendimento como esperado, foi a dor de dente $90,7 \%$ (127). Desses pacientes que se automedicavam $128(91,4 \%)$ relataram que sempre se automedicam quando sentem dor. (Quadro 2)

É inquestionável a relação entre automedicação e a dificuldade no acesso aos serviços de saúde. Dados epidemiológicos no Brasil quanto ao uso irracional de medicamentos são preocupantes e muitas internações hospitalares ocorrem devido ao seu uso indevido. Devido a isso em 2007 foi criado o Comitê Nacional para a Promoção do Uso Racional de Medicamentos por meio da Portaria no 427/07. Esse comitê é o responsável em desenvolver ações que ampliem o acesso da população à assistência farmacêutica visando diminuir o uso irracional de medicamentos ${ }^{1}$.

No estudo de Loyola et al., ${ }^{6}$ verificou-se a prevalência e os fatores associados ao uso de automedicação. Nesse estudo com amostra de 796 pacientes, 419 relataram uso exclusivo de medicamentos prescritos, 133 consumiram medicamentos prescritos e não-prescritos e 223 relataram uso exclusivo de medicamentos não prescritos. A amostra se caracterizou por ser de maioria feminina e de idade entre 40 e 59 anos $^{6}$.

Quadro 2: Motivo da procura do atendimento e a freqüência da automedicação.

\begin{tabular}{|c|c|c|}
\hline & $\mathrm{n}$ & $\%$ \\
\hline $\begin{array}{c}\text { Motivo da procura do } \\
\text { atendimento }\end{array}$ & & \\
\hline Dor de dente & 127 & $90,7 \%$ \\
Necessidade de restauração & 12 & $0,5 \%$ \\
Dor na gengiva & 1 & \\
\hline Frequencia na automedicação & & $91,4 \%$ \\
\hline Sempre que sente dor & 128 & $8,6 \%$ \\
Raramente & 12 & \\
\hline
\end{tabular}

Dados expressos em forma de frequência absoluta e percentual. 
Medicamentos anti-inflamatórios foram citados por 102 pacientes e os antibióticos por 45 pacientes. Ressalta-se que quanto a medicação, 7 pacientes fizeram o consumo de antibióticos juntamente a anti-inflamatórios. Não houveram diferenças entre os que relataram melhorias após o uso da medicação $(50,7 \%)$ e os que não obtiveram melhorias (49,3\%). (Quadro 3) Em um estudo realizado em Minas Gerais, ao se entrevistar 1664 usuários dos serviços de saúde, constatou-se que os medicamentos mais utilizados na automedicação são analgésicos e antipiréticos, já que possuem venda livre. ${ }^{6}$ Souza $\mathrm{Jr}$ et al, ${ }^{7}$ avaliou 67 pacientes que buscaram serviço odontológico e entre eles, 54\% afirmaram que se auto-medicavam, inclusive de antibióticos que normalmente restavam de outros tratamentos médicos e odontológicos.

Assim como nos demais campos da saúde, a Odontologia convive diariamente com a terapêutica medicamentosa. Entre os medicamentos mais prescritos se encontram os antimicrobianos e antiinflamatórios. Antibióticos têm a propriedade de inibir o crescimento de bactérias patogênicas eventualmente destruí-las. Esses medicamentos, em especial as penicilinas, podem provocar reações adversas, como alergia e hipersensibilidade. Além disso existe um fator importante a ser considerado que é a resistência bacteriana, que é aumentada quando o uso do medicamento é feito de forma errada. É importante a população ter a consciência dos riscos da auto-medicação, principalmente quando se trata de antibióticos, já que seu uso indiscriminado é sem dúvidas o principal causador da resistência bacteriana ${ }^{7}$.

No estudo de Vilarino et al. 1998,8 que caracterizou usuários que se automedicam, foram entrevistados 413 pessoas em Santa Maria- RS quanto ao uso indevido de medicamentos no último mês. Dos entrevistados, $69,9 \%$ utilizaram medicamentos e destes $76,1 \%$ o fizeram através de automedicação. Nesse estudo 0 ácido acetilsalicílico foi o medicamento mais utilizado. Dos fármacos utilizados na automedicação, $51,2 \%$ foram indicados por terceiros e $51,7 \%$ dessas indicações eram prescrições médicas emitidas em consultas anteriores.

Quadro 3: Classes de medicamentos usados sem prescrição e a melhoria com a automedicação.

\begin{tabular}{|c|c|c|}
\hline & $\mathrm{n}$ & $\%$ \\
\hline Medicamento tomado & & $5,0 \%$ \\
\hline $\begin{array}{c}\text { Não sabe o nome } \\
\text { Antiinflamatórios e } \\
\text { Analgésicos }\end{array}$ & 12 & $8,5 \%$ \\
\hline Ibuprofeno & 43 & $30,7 \%$ \\
Paracetamol & 47 & $33,5 \%$ \\
Dipirona & 33 & $23,5 \%$ \\
Antibióticos & 12 & $8,5 \%$ \\
Amoxicilina & & \\
Cefalexina & & \\
\hline Melhoria com a & & $50,7 \%$ \\
automedicação & 71 & $49,3 \%$ \\
\hline Sim & 69 & \\
Não & & \\
\hline
\end{tabular}

Dados expressos em forma de frequência absoluta e percentual.

Após responderem o questionário os pacientes foram atendidos pelo cirurgião-dentista da UBS para assim avaliar o motivo da dor e tomar alguma conduta quanto a isso. A inflamação dentária (pulpite) foi o diagnóstico da maioria dos casos 83 (59,0\%). Infecções dentárias ou apenas por raízes residuais ficaram em segundo plano somando juntas 48 dos casos. Quanto à conduta do cirurgião-dentista, a extração do dente foi o procedimento mais escolhido. (Quadro 4) 


Quadro 4: Diagnóstico e conduta do cirurgião-dentista após o atendimen
\begin{tabular}{|c|c|c|}
\hline & $\mathrm{n}$ & $\%$ \\
\hline Diagnóstico dado & & \\
\hline Inflamação dentária & 83 & $59,0 \%$ \\
Infecção dentária & 16 & $11,4 \%$ \\
Infecção por restos & 32 & $22,8 \%$ \\
radiculares & 8 & $5,7 \%$ \\
Trauma & 30 & $21,4 \%$ \\
Abcesso & & \\
\hline Conduta profissional & & $27,8 \%$ \\
\hline Abertura do dente & 39 & $45,0 \%$ \\
Exodontia & 63 & $27,1 \%$ \\
Mudança na & 38 & \\
medicação & & \\
\end{tabular}

Dados expressos em forma de frequência absoluta e percentual.

Sabe-se que as equipes de saúde da Estratégia de Saúde da Família (ESF) são formadas por médicos, enfermeiros, cirurgiões-dentistas e técnicos de enfermagem e saúde bucal, ou seja, o profissional farmacêutico não integra a equipe da ESF. Certamente a presença do farmacêutico, realizando as devidas orientações iria influenciar diretamente no uso racional dos medicamentos, especialmente em casos de urgência. (JESUS et al., 2013)

\section{Considerações Finais}

A automedicação é algo freqüente na vida das pessoas e seus riscos muitas vezes desconhecidos. A maioria entre a população estudada foi de pessoas com renda e escolaridade baixas e que frequentemente tomavam medicação sem orientação profissional.

Percebe-se a importância de trabalhar temas como uso racional de medicamentos, principalmente em locais onde a informação é menor, como no caso da UBS estudada, localizada em zona rural e a necessidade de inserção de profissionais farmacêuticos em unidades básicas de saúde da Estratégia de Saúde da Família.

\section{Referências}

1-Aquino DS. Por que o uso racional de medicamentos deve ser uma prioridade? Ciênc Saúde Coletiva 2008;31(1):733736.

2- Arrais PSD, Coelho HLL, Batista MCDS, Carvalho ML, Righi RE, Arnau JM. Perfil da automedicação no Brasil. Rev Saúde Pública 1997; 31(1):71-77.

3- Bisson MP. Farmácia Clínica e Atenção Farmacêutica, 1. ed. São Paulo: Medfarma, 2003.

4- Goodman LS, Gilman. As Bases Farmacológicas da Terapêutica. Analgésico Antipiréticos, Agentes Antiinflamatórios e Fármacos Utilizados no Tratamento da Gota, 10. ed, Rio de Janeiro: Guanabara Koogan, 2003.

5- Jesus APGAS, Yoshida NCP, Freitas JGAP. Prevalência da automedicação entre acadêmicos de Farmácia, Medicina, Enfermagem e Odontologia 2013; 40(2):151-164.

6- Loyola Filho Al, Uchoa E, Guerra HL, Firmo JOA, Lima-Costa MF. Prevalência e fatores associados à automedicação: resultados do projeto Bambuí. Rev Saúde Pública 2002; 36(1): 55-62.

7- Souza Junior UP, Pereira JV, Cavalcanti TM, Meo CADD. Avaliação do uso de medicamentos em odontologia: uma abordagem em saúde pública. Rev Bras Farm 2009;90(2):109-111. 
8- Vilarino JF. Perfil da automedicação em município do Sul do Brasil, Brasil. Rev Saude Pública 1998;32(1):43-49.

9- Viletti F, Sanches ACC. Uso indiscriminado e/ou irracional de antiinflamatórios não esteroidas (AINES) observados em uma farmácia de dispensação. Revista Visão Acadêmica 2009;10(1):69-76.

10- Wannmacher L, Pinehiro RM. Uso racional de anti-inflamatórios não esteróides, 1. Ed.Brasília: Editora do Ministério da Saúde, 2010.

\section{Claudia Santos Souza}

Endereço para correspondência - Rua: Rua: Carlos Vasconcelos, $n^{\circ}: 1338$

Bairro: Aldeota Cidade, CEP: 6-115170, Fortaleza, CE, Brasil.

E-mail: lidiarvm@gmail.com

Lattes: http://lattes.cnpq.br/5553352552277105

Lídia Audrey Rocha Valadas Marques - lidiavaladas@gmail.com

Márcio Glauber Lopes de Aguiar - marcioglauberla@gmail.com

Raquel Maria Trindade Fernandes - lidiavaladas@hotmail.com

Enviado em 22 de Julho de 2016. Aceito em 18 de Agosto de 2017. 